\title{
Tensile behaviour for mercerization of single kenaf fiber
}

\author{
Mohamad Ikhwan Ibrahim a, Mohamad Zaki Hassan ${ }^{a, ~}{ }^{*}$, Rozzeta Dolah ${ }^{\text {a }}$, Mohd Zuhri Mohamed \\ Yusoff ${ }^{b}$, Mohd Sapuan Salit ${ }^{b}$
}

a Razak Faculty of Technology and Informatics, Universiti Teknologi Malaysia, Jalan Sultan Yahya Petra, 54100 Kuala Lumpur

b Department of Mechanical and Manufacturing Engineering, Universiti Putra Malaysia, 43400 Serdang, Selangor, Malaysia

* Corresponding author: mzaki.kl@utm.my

\section{Article history}

Received 27 February 2018

Revised 28 March 2018

Accepted 21 May 2018

Published Online 3 December 2018

\begin{abstract}
A natural fiber including kenaf fibers that reinforce with polymeric composite has increased attention in the manufacturing industries. However, the poor adhesion between fiber and matrix are commonly encountered respectively to their compatibility nature namely hydrophilic and hydrophobic. Therefore, alkaline treatment has introduced to reduce the hydrophilic effect of natural fiber. This paper presents the treatment of single kenaf fibers following tensile test and predicted using analysis of variance (ANOVA). Here, the kenaf fibers were modified using $\mathrm{NaOH}$ at different solutions. Then, the single kenaf fiber was performed under ASTM D3379-89 standard. The results showed that kenaf fiber which treats with $\mathrm{NaOH}$ solution of $6 \%$ significantly offered the outstanding performance of the tensile behaviour.
\end{abstract}

Keywords: Tensile properties, kenaf fiber, alkaline treatment, analysis of variance

\section{INTRODUCTION}

Nowadays, varies of the material of composite have been introduced in order to improve the quality of life in society by the advancement of technologies in manufacturing industries. However, the acceleration of advanced technologies in the polymeric composite can contribute to a global environmental problem such as greenhouse gases which ultimately leads to global warming. Thus, many researchers find the alternative material of composite which is an environmentally friendly approach to substitute traditional polymeric composite materials. In order to replace the usage of synthetic polymer, material such as natural fiber is recommended for fulfils those applications.

The natural fiber has the potential to be a good material composite according to their environmental friendly, availability and has good strength and modulus. Hence, the natural fiber including kenaf is used for a wide range of application such as in automotive industry, where kenaf reinforced polypropylene composites utilized in the manufacturing of car component including door trim, inner board and other car components by Toyota Boshoku Corporation (Koronis, Silva, \& Fontul, 2013).

Even though, the natural fiber has problems to bonding with the polymer. It consists of cellulose, which is hydrophilic in nature. In order to overcome this problem, the alkaline treatment has been suggested. This treatment can reduce the hydrophilic effect on the fiber. However, based on previous works of literature, the optimizations of the main variable of those parameters are still unclear such as the concentration of a chemical solution, the duration for soaking the fiber in the chemical solution and the drying hours for natural fiber to dry. In order to find suitable values for these parameters, many experimental have done by researchers.

The purpose of this study is to identify the optimum solution of $\mathrm{NaOH}$ ranging from $0 \%$ to $8 \%$ under certain parameter of treatment to improve its tensile properties.

\section{LITERATURE REVIEW}

The application of kenaf fiber is widely used in composite industries. It has a good potential to be the reinforcement in the polymer composite. Thus, many researchers augment the research on the natural fiber composite. The natural fiber has a main problem which is to bonding with a polymer according to their hydrophilic in nature. It reveals their poor resistant to moisture, which leads to high water absorption (Sreekumar et al., 2009). Meanwhile, the polymer matrices are hydrophobic. Therefore, this will contribute to a weak bonding of the interfacial between natural fiber and polymer due to their incompatibility that resulting in poor mechanical properties (Sgriccia, Hawley, \& Misra, 2008). In order to overcome this problem, the alkaline treatment has been promoted. The alkaline treatment using sodium hydroxide $(\mathrm{NaOH})$ solutions can mercerization the hydrophilic effect of natural fiber (Jacob, Francis, Thomas, \& Varughese, 2006). Thus, the properties of natural fiber can optimize by alkaline treatment process (Gassan \& Bledzki, 1999).

Many attempts have been made to treat the fiber by varying the solution of the $\mathrm{NaOH}$, length of soaking and drying time. Some researchers found that the mercerization of kenaf fiber can improve its tensile properties at $6 \%$ of $\mathrm{NaOH}$ solution. Here, the fiber was soaked for 24 hours and then dried at $80^{\circ} \mathrm{C}$ for a day 6 . In contrast, Jacob et al. (2006), founded that $4 \%$ of $\mathrm{NaOH}$ which was dried at room temperature is the optimum solution to obtain the highest tensile strength properties. Nonetheless, the optimizations of those parameters are still unclear.

\section{METHODOLOGY}

\section{Material}

Kenaf fiber or also known as Hibiscus cannabinus was purchased from Lembaga Kenaf and Tembakau Negara (LKTN). The kenaf fiber 
was origin from Kelantan. The diameter of this kenaf fiber is approximately 75 to $125 \mu \mathrm{m}$. In order to measure the diameter of the kenaf, an optical microscope (Nikon LV150N) was used as showed in Figure 1. This photo was captured using bright field optical lens at 10x of magnification.

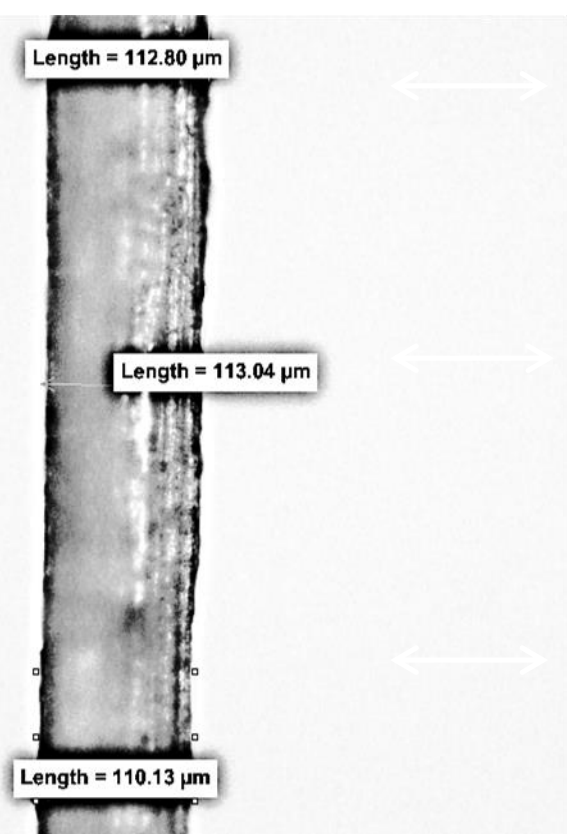

Fig. 1 Diameter measurement of kenaf fiber using the optical microscope.

\section{Alkaline treatment}

In this study, sodium hydroxide $(\mathrm{NaOH})$ solution was used to treat, modified and indirectly improve the specification of the kenaf fiber. The $\mathrm{NaOH}$ solution was prepared according to the weight per volume (w/v) basis. There are four solutions of $\mathrm{NaOH}$ solution were selected, namely $2 \%, 4 \%, 6 \%$ and $8 \%$. The kenaf fibers were soaked in $\mathrm{NaOH}$ solution for approximately 3 hours before dried at a temperature of $80^{\circ} \mathrm{C}$ for 6 hours.

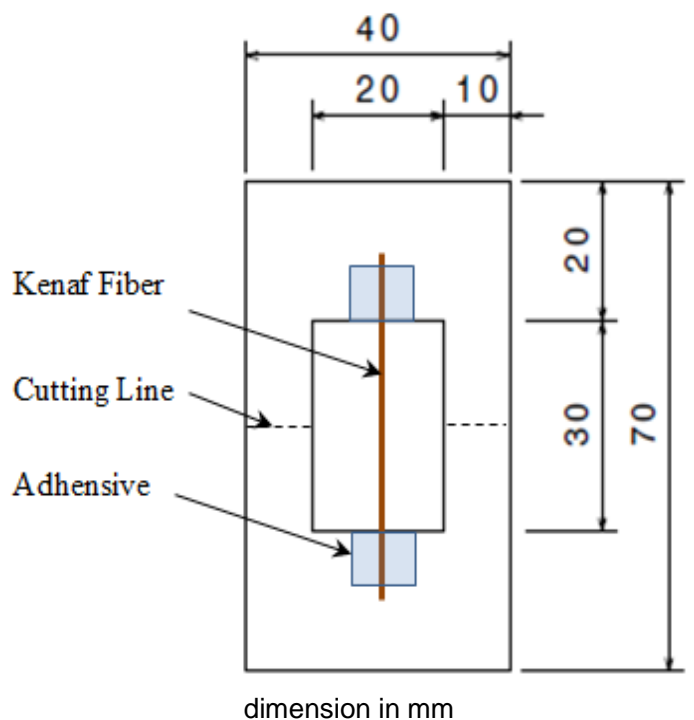

Fig. 2 Kenaf fiber specimen setup for tensile test.

\section{Preparation and tensile test of specimens}

The tensile specimen was prepared by sticking the fiber on the cardboard paper frame to prevent damage and easy handling of a fiber during testing as shown in Figure 2. Mechanical tests were performed in Universiti Putra Malaysia (UPM) using the universal testing machine at a crosshead speed of $0.5 \mathrm{~mm} / \mathrm{min}$. The tensile test was carried out according to ASTM D3379-89 standards. The ends of the cardboard paper frame were gripped by hydraulic clamps to align the fiber with the machine axis. The test begun after the cutting lines were cut off. The load-displacement trace was recorded in order to determine the tensile strength and young modulus of single kenaf fiber.

\section{RESULTS AND FINDINGS}

\section{Mechanical properties of single kenaf fiber}

Table 1 presents the results of tensile properties of treated and untreated of single kenaf fiber. It is clearly shown that the treated kenaf fiber with a solution of $6 \% \mathrm{NaOH}$ has significantly increased its tensile strength compared to the untreated fibre. This is similar to the finding from Nirmal et al. (2014), where they suggest a solution of $6 \% \mathrm{NaOH}$ will offer greater interfacial strength performance. Nonetheless, the untreated kenaf fiber still showing greater value than the treated at the solution of $2 \%, 4 \%$ and $8 \%$. According to table 1 , the cellulose of kenaf fiber has good young modulus and tensile strength than the solution treatment of $2 \%, 4 \%$ and $8 \%$. However, cellulose has a weak interfacial bonding with the polymer.

Table 1 Tensile properties for treated and untreated of single kenaf fiber.

\begin{tabular}{cccc}
\hline $\begin{array}{c}\text { Solution NaOH } \\
(\%)\end{array}$ & $\begin{array}{c}\text { Young } \\
\text { Modulus (GPa) }\end{array}$ & $\begin{array}{c}\text { Tensile } \\
\text { Strength (MPa) }\end{array}$ & $\begin{array}{c}\text { Fracture } \\
\text { Strain (\%) }\end{array}$ \\
\hline 2 & 4.28 & 25.28 & 1.28 \\
4 & 5.38 & 104.32 & 1.72 \\
6 & 11.88 & 267.69 & 2.07 \\
8 & 7.67 & 89.58 & 1.21 \\
untreated & 9.02 & 129.10 & 1.35 \\
\hline
\end{tabular}

Figure 3 showed the stress-strain curves of treated single kenaf fiber which is treated with the $\mathrm{NaOH}$ solution of $2 \%, 4 \%, 6 \%$ and $8 \%$. It is observed that kenaf fiber treated with $6 \%$ of $\mathrm{NaOH}$ offers the highest tensile strength, with a value of $268 \mathrm{MPa}$. Furthermore, the tensile strain for $6 \%$ treated kenaf fibre has outperformed approximately $30 \%$ higher than the others solution treatment. However, no significant differences in tensile strain are seen for treated fibre with $2 \%, 4 \%$ and $8 \%$, which lies between $1.25 \%$ and $1.5 \%$. A close observation on the tensile strength shows an increasing value as the solution percentage increased, even though a dramatic drop occurs at $8 \%$ solution. This may be due to higher solution treatment agent has eroded the fibers and reduce some of its properties.

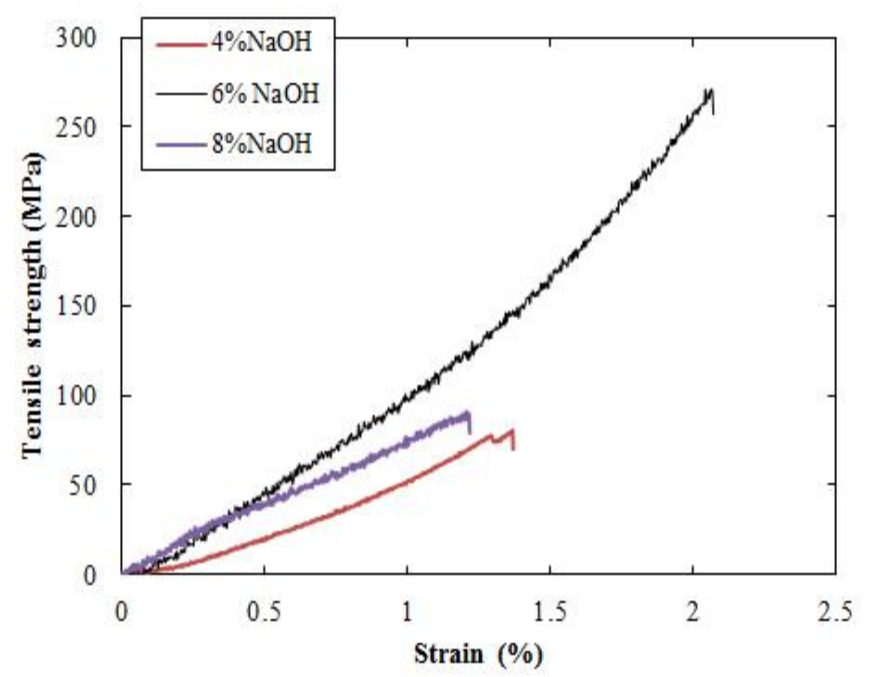

Fig. 3 Stress-strain curve of single kenaf fiber following tensile test.

The comparison of tensile strength and Young's modulus for treated fiber under several of $\mathrm{NaOH}$ solution are shown in Figure 4. Clearly, both tensile strength and Young's modulus for $6 \% \mathrm{NaOH}$ shows the maximum values and the properties decreases at $8 \%$ of $\mathrm{NaOH}$ solution. It can be suggested that over the treatment of the fiber 
can decrease their mechanical properties. An excessive solution of $\mathrm{NaOH}$ would certainly degrade the fiber and result of a reduction in the tensile strength of the fiber as studied by 1 (Mwaikambo \& Ansell, 2002). On the other hand, the insufficient chemical solution would also reduce the tensile behavior of treated fiber as compared to untreated fiber.

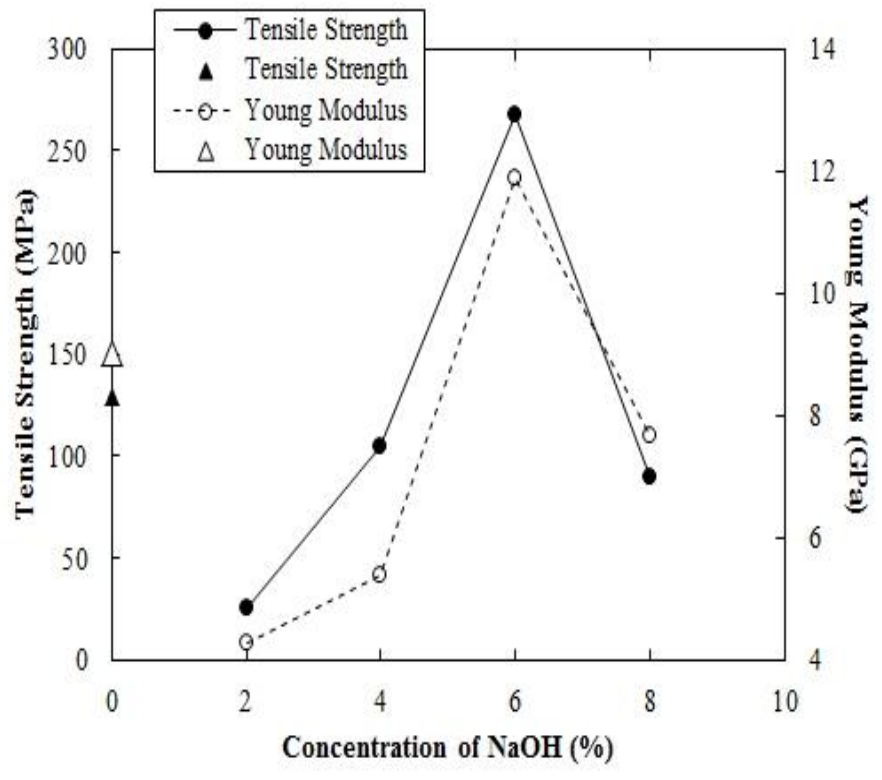

Fig. 4 Typical of tensile strength and Young modulus curves of the treated and untreated single kenaf fiber.

\section{Analysis of variance for mechanical properties of kenaf fiber}

Table 3 and 4 showed the result of one-way analysis of variance (ANOVA) for difference $\mathrm{NaOH}$ solution regarding tensile strength and modulus respectively. The result of ANOVA analysis in Table 1 showed the F-Ratio of tensile strength is 9.19 and their P-value is 0.0288. On the other table, table 2 showed F-Ratio of tensile modulus is 12.56 and their P-value is 0.0167. Since the P-value of F-test of tensile strength and modulus are less than 0.05 , their results are significant at $\mathrm{p}<0.05$. The result of the ANOVA test in table 1 and 2 are the significant value of $\mathrm{NaOH}$ solution, it can be concluded that the increasing $\mathrm{NaOH}$ solution has affected the tensile strength and modulus of fiber.

Table 3 ANOVA test for the tensile strength of $\mathrm{NaOH}$ solution.

\begin{tabular}{lccccc}
\hline Source & ss & df & MS & F-Ratio & P-value \\
\hline Between & 71619.76 & 3 & 23873.25 & 9.19 & 0.0288 \\
Groups & 10387.25 & 4 & 2596.81 & & \\
Within Groups & 82007.01 & 7 & & & \\
\hline Total & \multicolumn{5}{l}{}
\end{tabular}

Table 4 ANOVA test for tensile modulus of $\mathrm{NaOH}$ solution.

\begin{tabular}{lccccc}
\hline Source & ss & df & MS & F-Ratio & P-value \\
\hline Between & 67.83 & 3 & 22.61 & 12.56 & 0.0167 \\
Groups & 7.2 & 4 & 1.8 & & \\
Within Groups & 75.03 & 7 & & & \\
\hline Total & & &
\end{tabular}

\section{CONCLUSION}

In this study, the single kenaf fiber has been treated with a different solution of $\mathrm{NaOH}$. Then, the tensile properties of the single kenaf fiber were determined using an Instron universal testing machine. The results showed that the optimum tensile properties are obtained at $6 \%$ of $\mathrm{NaOH}$ solution. It is found that an insufficient of the chemical solution will decrease the tensile properties, whereas the excessive solution of $\mathrm{NaOH}$ can easily erode the fiber. The performance of properties of fiber also can enhance with the optimum time of drying and soaking.

\section{ACKNOWLEDGEMENT}

Appreciation is given to Universiti Teknologi Malaysia for funding (GUP Tier 1 Grant No. Q.K130000.2540.15H70 and FRGS Grant No. R.K130000.7840.4F880) this research work. The authors would also like to thanks to Universiti Putra Malaysia for allowing us to use their facilities.

\section{REFERENCES}

Gassan, J., Bledzki, A. K. 1999. Possibilities for improving the mechanical properties of jute/epoxy composites by alkali treatment of fibres. Composites Science and Technology, 59, 9, 1303-1309.

Jacob, M., Francis, B., Thomas, S., Varughese, K. 2006. Dynamical mechanical analysis of sisal/oil palm hybrid fiber-reinforced natural rubber composites. Polymer Composites, 27, 6, 671-680.

Koronis, G., Silva, A., Fontul, M. 2013. Green composites: A review of adequate materials for automotive applications. Composites Part B: Engineering, 44, 1, 120-127.

Mwaikambo, L. Y., Ansell, M. P. 2002. Chemical modification of hemp, sisal, jute, and kapok fibers by alkalization. Journal of Applied Polymer Science, $84,12,2222-2234$

Nirmal, U., Lau, S. T., Hashim, J. 2014. Interfacial adhesion characteristics of kenaf fibres subjected to different polymer matrices and fibre treatments. Journal of Composites, 2014, 1-12.

Sgriccia, N., Hawley, M., Misra, M. 2008. Characterization of natural fiber surfaces and natural fiber composites. Composites Part A: Applied Science and Manufacturing, 39, 10, 1632-1637.

Sreekumar, P., Thomas, S. P., marc Saiter, J., Joseph, K., Unnikrishnan, G., Thomas, S. 2009. Effect of fiber surface modification on the mechanical and water absorption characteristics of sisal/polyester composites fabricated by resin transfer molding. Composites Part A: Applied Science and Manufacturing, 40, 11, 1777-1784. 